Interdisciplinary Science Reviews

March 2008, Volume 33, Number 1, Pages 95-103

http://dx.doi.org/10.1179/030801808X260031

(c) 2008 Institute of Materials, Minerals and Mining. Published by

Maney on behalf of the Institute
Archimer

Archive Institutionnelle de l'Ifremer http://www.ifremer.fr/docelec/

\title{
Enhancing citizen contributions to biodiversity science and public policy
}

\author{
Couvet $\mathrm{D}^{1,{ }^{*}}$; Jiguet $\mathrm{F}^{1} ;$ Julliard $\mathrm{R}^{1}$; Levrel $\mathrm{H}^{2}$; Teyssedre $\mathrm{A}^{3}$ \\ 2 UMR AMURE, Marine Economics Department, Ifremer, Brest Centre, BP 70, 29280, Plouzané, France
}

${ }^{1}$ UMR 5173 MNHN-CNRS-UPMC, 55 rue Buffon, 75005 Paris, France

${ }^{3}$ DEGB, MNHN, 36 rue Geoffroy St Hilaire, 75005 Paris, France

*: Corresponding author : Couvet D., email address : $\underline{\text { couvet@mnhn.fr }}$

\begin{abstract}
:
Citizen science, defined as participation of the general public in scientific research, could significantly help scientists to address biodiversity issues, through (i) monitoring the state of biodiversity, (ii) framing indicators which synthesise and communicate information on the state of biodiversity, (iii) building scenarios to evaluate the plausible consequences of different policies. A key asset of citizen science is that participating citizens disseminate the information they gain, thereby increasing the profile of issues being researched. We review further benefits associated with biodiversity monitoring, indicators and policy scenarios, envisioned as collaborative tools between scientists and citizens. Such collaboration promotes both the scientific adequacy and social legitimacy of these tools, so that they can meaningfully inform debates and decisions on public policy.
\end{abstract}

Our environmental predicament has been considered to result above all from a combination of ignorance and institutional failure.1 In this regard, biodiversity stands out as lacking synthetic reporting addressing issues considered to be important by the general public and decision-makers, which impairs rational and ambitious policies in favour of sustaining biodiversity. 2 Citizen science, defined as participation of the general public in scientific research,3 could significantly improve knowledge and decision-making in the field of biodiversity, based on three different types of activities: (i) monitoring the state of biodiversity, (ii) framing indicators which synthesise and communicate information on the state of biodiversity, (iii) building scenarios to evaluate the plausible consequences of different policies. Based on the significant literature concerning citizen science and more generally the participative approach to developing indicators, scenarios or data,4 we review in this paper the relevance of citizen science with regard to these three activities, the large synergy that exists between them, and the conditions for success, especially in respect of long-term experience in the case of monitoring.

We argue here that citizen science applied to conservation can be perceived as an extensive collaboration between scientists and citizens. One important benefit for scientists is that participating citizens bring the information needed, supplementing professionals, especially in the case of monitoring. Moreover, compared to traditional science, where scientists deliver information of use to citizens, citizen science in the realm of conservation brings further scientific advantages in terms of improving the relevance of indicators and scenarios, facilitating the identification of key issues in relation to the dynamics of 
biodiversity, and orienting public policies and actions towards adaptive management of ecosystems, favouring the adaptive/reactive management of ecosystems through concerted public policy.

\section{DEVISING BIODIVERSITY MONITORING SYSTEMS}

Relevant knowledge about the state of biodiversity requires biodiversity monitoring systems. To be informative, such systems require information on species, categorised into different groups (vertebrates, invertebrates, plants, etc.), as well as on the states of ecosystems. ${ }^{5}$ Monitoring of a large number of species is required to give an adequate representation of the complexity of biodiversity and the diversity of ecosystem functions. Numerous monitoring sites are necessary to disentangle the effects of the numerous environmental factors associated with global change, from habitat fragmentation to climate change, the importance of which varies with spatial scale, from the local to the global.

\section{Citizen monitoring systems}

Citizens can provide the large number of observations needed, supplementing professional monitoring schemes such as remote sensing. Citizen science has already provided a major monitoring system, documenting variations of abundance in common bird species on the scale of continents (North America and Europe), for more than twenty-five years; scientific success has resulted, as shown by papers in major journals in the field of ecology. ${ }^{6}$ The long-term potential of citizen science schemes can be estimated from a review of the new but increasingly complex themes now developed, ecological dynamics of invasive species for example, or studies of genetic structures and epidemiological dynamics on large spatial scales. ${ }^{7}$

Collecting huge amounts of ad hoc observations from people does not necessarily deliver good science, and merely managing information is not enough. Adequate survey design, sampling strategies and field methods are necessary in successful citizen science projects. Scientific excellence is required to achieve simple but rigorous protocols, in order to attract numerous observers while providing sufficient data quality. In other words, protocols have to be developed based not only on scientific grounds but also on observers' motivations and abilities. Scientific excellence is also required to develop adequate statistical tools to assess data quality and manage heterogeneity in such quality, to reduce bias, and finally to analyse the data. ${ }^{8}$

Technical and scientific tools exist to generalise present experience with birds and butterflies to other groups - bats, insects, plants, etc. - in order to provide a general biodiversity monitoring system that takes into account a large variety of organisms. ${ }^{9}$ Opportunities exist for citizen contributions to broader aspects of biodiversity for which present monitoring is lacking, concerning ecosystems, landscape structures and ecosystem services.

The public implied in this research might depend on the type of biodiversity monitored. The farming community might represent an efficient network in relation to monitoring soil fauna, owing to farmers' awareness of the relationship between this component of biodiversity and soil fertility. Gardeners on the other hand could be a source of knowledge on urban biodiversity, and anglers could collect information on river biodiversity. 


\section{Citizen monitoring versus professional monitoring}

Professional biodiversity monitoring systems do exist, involving on the one hand remote sensing - documenting landscape fragmentation and more generally land use - but also the close monitoring of exploited species and water quality, producing extensive data on bacteria and micro-organism communities. The relevance of citizen monitoring systems depends on their relative costs and benefits compared with professional systems. The comparison must take account of financial costs (generally much lower with trained volunteer observers), the social legitimacy of the results (this is discussed below in relation to indicators), and also the resilience of the monitoring system, i.e. maintenance of the network over years, as long time-series are more valuable in scientific terms.

\section{Resilience of citizen monitoring systems}

Experience with bird monitoring systems, which have endured for more than fifty years in the US, suggests high resilience of citizen monitoring systems. Resilience is usually impaired by variations in societal priorities, and hence of financial support. Professional schemes fail readily when institutional support collapses, whereas citizen benevolence might lead to maintenance in the case of such adverse events, at least temporarily.

Resilience of citizen monitoring systems might benefit from organisation of the monitoring scheme in hierarchical networks, merging local groups of observers at different spatial scales. Scientists can disentangle processes relevant at each scale from those at higher ones, using comparative analyses of biodiversity dynamics between areas. Local monitoring networks produce evaluations of the relative state of biodiversity in the area monitored, which are of great interest for the observers. Added to the recognition of their key role in biodiversity monitoring and research, this insight into local biodiversity boosts the long-term commitment of observers to the network. Overall, such hierarchical organisation facilitates multi-scale coordination, analysis and funding, with beneficial reciprocal interactions; higher-scale nodes bring protocols, hence scientific legitimacy, while lower-scale nodes bring the data (Fig. 1).

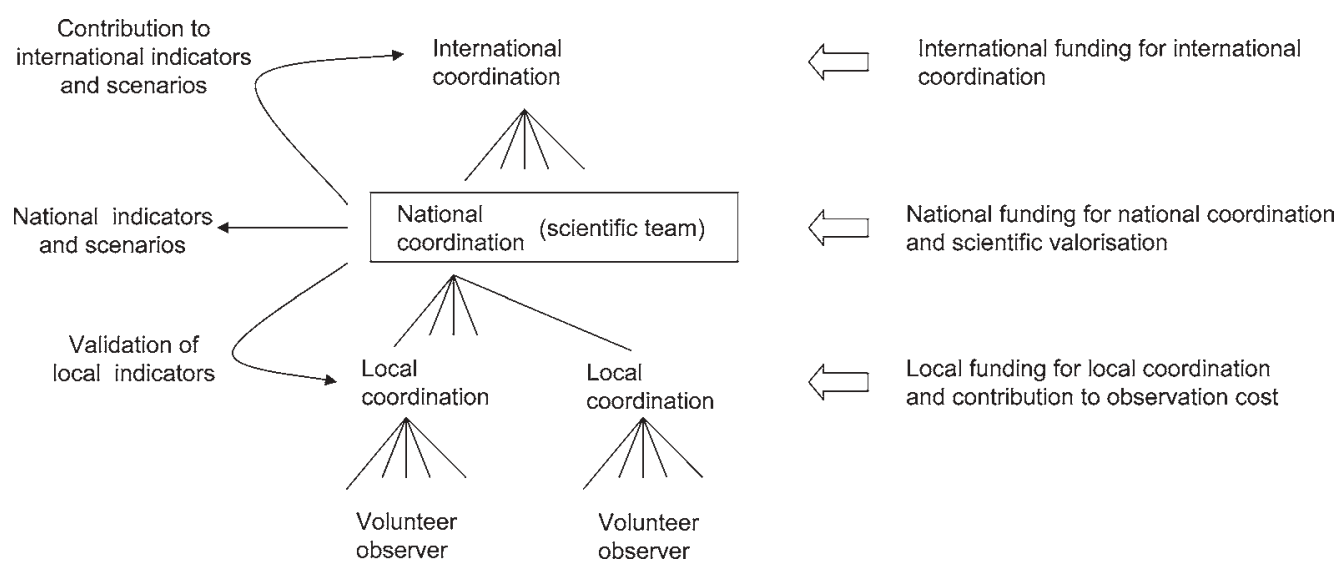

1 A general scheme for the hierarchical organisation of citizen science in the field of biodiversity monitoring, indicators and scenarios 
Hierarchical organisation brings diversity of actors, modularity of the network, and tightness of feedback between local observers and their financial support. Note that these are the three criteria considered to be necessary for the resilience of any complex system. ${ }^{10}$ Overall, one therefore expects greater resilience of citizen monitoring systems than of professional ones.

\section{CHOOSING RELEVANT BIODIVERSITY INDICATORS}

Biodiversity indicators quantify the relationships between biodiversity and human societies. Indicators are necessary in the case of large-scale effects, in space and time. For example, bird community dynamics at a given site depend on numerous factors, some acting at large scales, such as climate, and others at the scale of the landscape, for example the type of agriculture practised. ${ }^{11}$ As a result, observers cannot directly evaluate factors responsible for the community variations they observe. Based on comparison of communities at numerous sites, indicators quantify the effects of different factors, and stochastic effects are discarded.

Besides their scientific value, indicators have to be 'widely accepted, and easily understood'. ${ }^{12}$ Citizen science helps scientists to gear their efforts towards a description of biodiversity which takes into account what is considered acceptable and understandable by the public, as these criteria are not commonly taken into account in scientific practice. ${ }^{13}$ Indeed, indicators developed by scientists without citizen contributions, for example for fisheries, lead to recurring controversies on the state of fish-stocks, and hence around decisions, between scientists, managers and fishermen, one reason being that there is no agreement on the relevant indicator. ${ }^{14}$

Looking for public acceptability and understanding might also contribute to reaching a scientific consensus on biodiversity dynamics. There are numerous scientific ways to devise indicators, relying on species diversity, taking into account functional differences among species abundances. ${ }^{15}$ Because different scientific disciplines emphasise different aspects of biodiversity - systematics emphasises species diversity, while population ecology stresses community abundances - a scientific consensus is rather difficult to reach. Public response to different indicators might be a criterion of choice.

Indeed, several biodiversity indicators have been framed by NGOs which have issued from citizen science. For example, among the twelve headline indicators of European sustainable development, the biodiversity indicator 'state of farmland birds' ${ }^{16}$ has been framed - and is documented - by EBCC, an amateur association of ornithologists. Citizen involvement in the methodology of indicator development also exists among the set of CBD (Convention on Biological Diversity) indicators, given the large role played by NGOs in identifying many of the indicators and in pushing for their adoption. ${ }^{17}$

\section{PARTICIPATORY SCENARIOS}

Through comparing the effects of different policies and bringing information to stakeholders, biodiversity scenarios aim to help decision-making. Compared to other scenarios, scenarios based on citizen monitoring, or 'participatory scenarios', might be advantageous for three reasons, detailed further below: in terms of public audience; in producing effective possibilities for identifying significant heterogeneities in the relationships 
between humans and biodiversity; and for analysing the outcome of the manifold interactions between stakeholders. Thus, in integrated assessments such as those promoted through the Millennium Ecosystem Assessment (MEA) (see www.maweb.org), the full involvement of stakeholders is a key requirement. ${ }^{18}$

\section{Public audience}

Owing to their larger public audience, participatory scenarios should contribute significantly to a choice between policies. Participatory scenarios bring larger public audiences because a larger number of individuals are involved and are willing to broadcast the results. The greater the public awareness of scenarios, the more likely that these scenarios will influence policies, for three sets of reasons: first, individuals will be more likely to alter their behaviour when environmental consequences are scientifically demonstrated; ${ }^{19}$ second, new policies involving intricate socio-economic consequences should be easier to enforce when their consequences are clearly explained (such policies concern for example economic incentives and disincentives to avoid the 'tragedy of the commons', specifically over-exploitation and under-delivery of common resources);, ${ }^{20}$ third, 'what if scenarios are strongly connected with alternative perceptions of a common problem and allow clarification of the main sources of divergence (e.g. amongst the four MEA scenarios ${ }^{21}$ ).

\section{Identification of significant heterogeneities}

Participatory scenarios could be an important tool for identifying the range of human responses to the diversity of environmental and socio-economic conditions. Both indicators and scenarios ought to characterise the relationships between the environment and the different stakeholders, through productive, consumptive and recreational activities, in order to carry out a relevant analysis of such socio-ecosystems. ${ }^{22}$ A relevant analysis requires the significant sources of heterogeneity in these relationships to be taken into account, as well as an adequate representation of the diversity of motivations and responses among human actors. ${ }^{23}$

Professional scientists might overlook the diversity in the relations between humans and the rest of nature, as certain social groups are poorly represented in ecological research. ${ }^{24}$ Participatory scenarios might facilitate identification of these heterogeneities, since the diversity of citizen viewpoints will add to the diversity of viewpoints already considered by professional scientists. For example, birdwatchers belong to a wide variety of socio-economic categories, ${ }^{25}$ thus representing a large diversity of human responses to environmental challenges.

\section{Analysing the effects of interactions between stakeholders}

Participatory scenarios contribute to exploration of the complexity of interactions between stakeholders. Given the large number of interactions to consider, a large number of experimenters might decisively contribute to the analysis of these interactions. A related example illustrating such advantage is the large-scale participation of citizens in modelling exercises, used for instance in the large-scale computer model of the climate change project. ${ }^{26}$

To analyse interactions between stakeholders, participatory scenarios can rely on interactive techniques such as multi-agent modelling (MAM). MAM, associated with companion modelling, is a tool for exploring and simulating stakeholder reactions to different situations, and more importantly to responses of interacting stakeholders, the 
effects of each (simulated) participant's action(s) depending on the others' ${ }^{27}$ This can be more generally formalised as adaptive learning, where new institutions and new models are regularly tested by stakeholders to decide on their relevance. ${ }^{28}$

Modelling social interactions contributes to an understanding of which conditions lead to the benefits of cooperative relationships. ${ }^{29}$ Stakeholder participation in scenarios might help to explore and understand the different motivations, the outcomes of (non-) cooperative interactions, and most generally to interrogate the overall functioning of the ecosystem depending on the different combined actions, that is to define the ecosystem resilience. ${ }^{30}$ Resilience depends on the set of stakeholders present and on their reactions and interactions. As such, resilience cannot be a scientific construction independent of any interaction with citizens, and indeed citizen participation is expected (see the Resilience Alliance's website at www.resalliance.org). The question remains of how participatory scenarios can be organised, independently or within other contributions of citizen science, in terms of deliberative methods, citizen conferences and focus groups. ${ }^{31}$

\section{CONCLUSION: SYNERGY BETWEEN CITIZEN MONITORING, INDICATORS AND SCENARIOS}

Citizen monitoring offers the potential to inform relevant biodiversity indicators, which may then themselves contribute to building meaningful scenarios. Such synergy between citizen monitoring, indicators and scenarios has occurred in the case of the expected impact of genetically-modified crops and agrienvironmental schemes on birds. ${ }^{32}$ Note that citizen monitoring brings information on the expected effects of individual action without the use of indicators and scenarios, in cases where individual action has a direct effect on biodiversity. This is the case with garden bird-watches and butterfly monitoring projects, where bird and butterfly abundances depend directly on plants and pesticides used by monitoring citizens. ${ }^{33} \mathrm{~A}$ further synergy is that indicators and scenarios based on citizen monitoring might result in greater public legitimacy, and hence influence decision-making, because a significant portion of the public generates the information and/or knows monitoring methods and observers, leading to positive feedback between monitoring, indicators and scenarios: documenting biodiversity indicators might become a major impetus to participating in monitoring schemes.

Overall, synergy between indicators, data and scenarios is firstly based on their complementarities (Fig. 2). Indeed, the quality of the indicator depends on the data available for implementing it. Next, sense-making indicators supply user-friendly tools for discussing the scenario outputs. On the other hand, simulations based on scenarios make the indicators more dynamic and lively and help to articulate long-term dynamics and short-term preferences. As a result, citizen science in the field of biodiversity, with a proper association between monitoring, indicators and scenarios (Figs. 1 and 2), combining scientific rigour and societal understanding, should facilitate societal adaptation to environmental challenges.

Finally, science and development could benefit from such projects in developing countries. Setting up a citizen biodiversity monitoring system, generating indicators and scenarios, might be a low-tech, high-intellect project, involving theoretical ecology, statistics and modelling. In other words, it could be a wide-ranging educational project, with significant scientific and social outputs. 


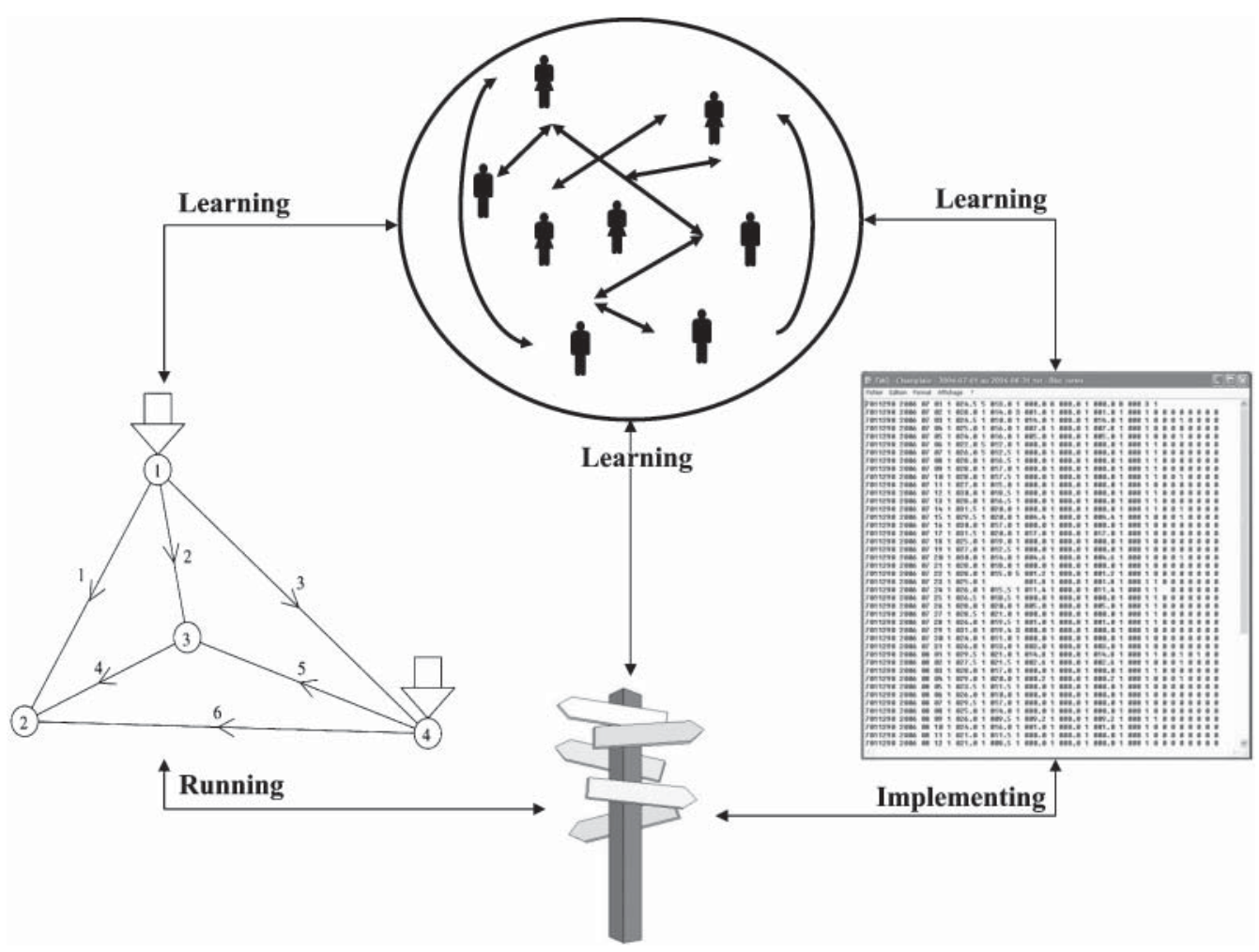

2 Synergy between indicators, models and data in a collective learning-by-doing process

\section{NOTES}

1. P. Dasgupta, S. Levin and J. Lubchenko: 'Economic pathways to ecological sustainability', Bioscience, 2000, 50, 339-345; T. Dietz, E. Ostrom and P. C. Stern: 'The struggle to govern the commons', Science, 2003, 302, 1907-1912; P. Lal, H. Lim-Applegate and M. C. Scoccimarro: 'The adaptive decision-making process as a tool for integrated natural resource management: focus, attitudes, and approach', Conservation Ecology, 2001, 5, www.consecol.org/vol5/iss2/art11; E. Ostrom: Governing the Commons; 1990, Cambridge, Cambridge University Press.

2. M. Loreau and A. Oteng-Yeboah: 'Diversity without representation', Nature, 2006, 442, 245-246.

3. A. Irwin: Citizen Science; 1995, London, Routledge.

4. C. B. Cooper, J. Dickinson, T. Phillips and R. Bonney: 'Citizen science as a tool for conservation in residential ecosystems', Ecology and Society, 2007, 12, www.ecologyandsociety.org/vol12/iss2/art11; R. Costanza. and M. Ruth: 'Using dynamic modeling to scope environmental problems and build consensus', Environmental Management, 1998, 22, 183-195; T. R. Gurung, F. Bousquet and G. Trébuil: 'Companion modeling, conflict resolution, and institution building: sharing irrigation water in the Lingmuteychu watershed, Bhutan', Ecology and Society, 2006, 11, www.ecologyandsociety.org/vol11/iss2/ art36; H. Levrel, M. Etienne, C. Kerbiriou, C. Le Page and M. Rouan: 'Co-modeling processes, negotiations and power relationships: some outputs from a MAB project in the island of Ouessant', Society $\ll$ Natural Resources, 2008, 21; M. S. Reed, E. D. G. Fraser and A. J. Dougill: 'An adaptive learning process for developing and applying sustainability indicators with local communities', Ecological Economics, 2006, 59, 406-418; E. Rouwette, J. Vennix and T. van Mullekom: 'Group model building effectiveness: a review of assessment studies', System Dynamics Review, 2002, 18, 5-45.

5. A. Balmford et al: 'The Convention on Biological Diversity's 2010 target', Science, 2005, 307, 212-213. 
6. R. D. Gregory, A. van Strien, P. Vorisek, A. W. Gmeling, D. G. Noble, R. P. B. Foppen and D. W. Gibbons: 'Developing indicators for European birds', Philosophical Transactions of the Royal Society B: Biological Sciences, 2005, 360, 269-288; F. Jiguet, R. Julliard, C. D. Thomas, O. Dehorter, S. E. Newson and D. Couvet: 'Thermal range predicts bird population resilience to extreme high temperatures', Ecology Letters, 2006, 9, 1321-1330.

7. P. R. Hosseini, A. A. Dhondt and A. P. Dobson: 'Spatial spread of an emerging infectious disease conjunctivis in house finches', Ecology, 2006, 87, 3037-3046; D. Simberloff: 'Eradication: preventing invasions at the outset', Weed Science, 2003, 51, 247-253.

8. C. Newman, C. D. Buesching and D. W. Macdonald: 'Validating mammal monitoring methods and assessing the performance of volunteers in wildlife conservation - "sed custodiet ipsos custodies?", Biological Conservation, 2003, 13, 189-197.

9. F. A. Bisby: 'The quiet revolution: biodiversity informatics and the internet', Science, 2000, 289, 2309-2314.

10. B. Walker and M. Salt: Resilience Thinking, 2007, Washington, DC, Island Press.

11. R. Julliard, F. Jiguet and D. Couvet: 'Common birds facing global changes: what makes a species at risk?', Global Change Biology, 2004, 10, 148-154.

12. A. Balmford et al:: 'The Convention on Biological Diversity's 2010 target' (see Note 5).

13. H. Levrel and M. Bouamrane: 'Instrumental learning and sustainability indicators: outputs from co-construction experiments in West African biosphere reserves', Ecology and Society, to be published.

14. R. Hilborn: 'Moving to sustainability by learning from successful fisheries', Ambio, 2007, 36, 296-303.

15. S. T. Buckland, A. E. Magurran, R. E. Green and R. M. Fewster: 'Monitoring change in biodiversity through composite indices', Philosophical Transactions of the Royal Society B: Biological Sciences, 2005, 360, 243-254

16. 'Sustainable development indicators of the European Union. Indicators of management of natural resources. Population index of farmland birds', Eurostat, 2007, available online at http://epp.eurostat. ec.europa.eu.

17. 'Monitoring and indicators: designing national-level monitoring programmes and indicators', UNEP/ CBD/SBSTTA/9/10, Subsidiary Body on Scientific, Technical and Technological Advice (SBSTTA), November 2003, www.cbd.int/doc/meetings/sbstta/sbstta-09/official/sbstta-09-10-en.pdf.

18. See www.wri.org/biodiv/pubs_description.cfm?PubID $=4154$.

19. M. Milinski, D. Semmann, H. J. Krambeck and J. Marotzke: 'Stabilizing the earth's climate is not a losing game: supporting evidence from public good experiments', Proceedings of the National Academy of Sciences, 2006, 103, 3994-3998.

20. J. Rosales: 'Economic growth and biodiversity loss in an age of tradable permits', Conservation Biology, 2006, 20, 1042-1050.

21. Millennium Ecosystem Assessment: Ecosystems and Human Well-being: Synthesis; 2005, Washington, DC, Island Press.

22. Ecosystems and Human Well-Being (see Note 20).

23. J. Pretty: 'Social capital and collective management of resources', Science, 2003, 302, 1912-1916; S. J. Wright and H. C. Muller-Landau: 'The future of tropical forest species', Biotropica, 2003, 38, 287-301; M. Janssen and B. de Vries: 'Climate change and society responses', Ecological Economics, 1998, 26, 43-65.

24. B. M. Starzomski, B. J. Cardinal, J. A. Dunne, M. J. Hillery, C. A. Holt, M. A. Krawchuk, M. Lage, S. McMahon and M. C. Melnychuk: 'Contemporary visions of progress in ecology and thoughts for the future', Ecology and Society, 2004, 9, www.ecologyandsociety.org/vol9/iss1/art14.

25. D. E. Allen: Naturalists and Society; 2001, Aldershot, Ashgate.

26. C. Lundmark: 'Modeling change', Bioscience, 2006, 56, 456.

27. T. R. Gurung et al: 'Companion modeling, conflict resolution, and institution building' (see Note 4).

28. J. Wilson, L. Yan and C. Wilson: 'The precursors of governance in the Maine lobster fishery', Proceedings of the National Academy of Sciences, 2007, 104, 15212-15217.

29. V. Galasz: 'Social-ecological resilience and social conflict: institutions and strategic adaptation in Swedish water management', Ambio, 2005, 34, 567-572.

30. B. Walker and M. Salt: Resilience Thinking (see Note 10).

31. P. C. Stern: 'Deliberative methods for understanding environmental systems', Bioscience, 2005, 55, 976-982. 
32. S. J. Butler, J. A. Vickery and K. Norris: 'Farmland biodiversity and the footprint of agriculture', Science, 2006, 315, 381-384.

33. M. Evans et al: 'The neighborhood nestwatch program', Conservation Biology, 2005, 19, 589-594; G. D. Daniels and J. B. Kirkpatrick: 'Does variation in garden characteristics influence the conservation of birds in suburbia?', Biological Conservation, 2006, 133, 326-335.

Denis Couvet (to whom correspondence should be addressed: couvet@mnhn.fr) is a full professor at the Muséum national d'Histoire naturelle and the Ecole polytechnique in Paris, and Director of UMR 5173. His research concerns conservation biology, biodiversity monitoring systems, indicators and scenarios to analyse the effects and consequences of global change on living organisms.

Frédéric Jiguet is an associate professor at the Muséum national d'Histoire naturelle. A specialist in conservation biology, he develops and runs the Breeding Bird Survey scheme at the French national scale ('STOC' programme, including a thousand observers), in association with the European Bird Census Council. His research concerns the impact of global change and especially climate change on bird communities, using indicators, consequences for the functioning of bird communities, its mechanisms, and the development of scenarios, to consider the expected effects of different policies on living communities.

Romain Julliard is an associate professor at the Muséum national d'Histoire naturelle. Specialised in conservation biology, he develops and runs biodiversity observatories at the French national scale (Vigie Nature' project), based on monitoring of common species and the involvement of voluntary observers (citizen science). His research concerns the functional homogenisation of biodiversity, its mechanisms (reorganisation of communities under the influence of global changes) and applications (development of biodiversity indicators).

Harold Levrel completed a PhD dissertation in ecological economics at UMR 5173, at the Muséum national d'Histoire naturelle. After a postdoctoral position at the CNRS in Paris, he is now a research associate in the Ifremer marine economics department. His work focuses on indicators relating to interactions between biodiversity dynamics and socio-economic dynamics.

Anne Teyssèdre (http://anne.teyssedre.free.fr) is a consultant and scientific writer on ecology. For nearly twenty years she has written or coordinated books and DVDs as well as papers, booklets and reports in ecology and evolutionary sciences. As scientific adviser or author, she has worked on numerous films, exhibitions and scientific websites on biodiversity. For the last five years she has been conducting research and communication on the present biodiversity crisis - its extent, its risks, and new conservation strategies, methods and tools. 